\title{
Formação docente inicial: perfis socioeconômico-cultural, leitor e escritor de alunos do curso de Pedagogia
}

\author{
Initial teacher education: socioeconomic-cultural, reading and \\ writing profiles of pedagogy students
}

\section{Formación docente inicial: perfiles socioeconomico-cultural, lectura y escritura de alumnos del curso de Pedagogia}

\author{
Ana Luzia Videira Parisotto ${ }^{1}$ \\ http://orcid.org/0000-0001-9786-745X \\ Michelle Mariana Germani² \\ http://orcid.org/0000-0001-8387-320X
}

\begin{abstract}
Resumo: É importante que a abertura para o transformar-se em professor seja iniciada ainda na graduação que deve propiciar experiências formativas que possibilitem o desenvolvimento de conhecimentos necessários à prática profissional, pois é o momento de se construir uma base para o desempenho profissional futuro. nessa perspectiva, o objetivo do presente artigo é descrever e analisar o perfil socioeconômico-cultural, de leitura e de escrita do aluno ingressante no curso de pedagogia, em 2017, por meio da aplicação de um questionário. a pesquisa é de abordagem qualitativa, de caráter descritivo-analítico, cuja amostra contou com 79 estudantes: 36 do turno vespertino e 43 do período noturno. os dados apontam que os alunos do curso de pedagogia são predominantemente do sexo feminino,
\end{abstract}

1 É licenciada em Letras pela Faculdade de Ciências e Letras, Unesp/Assis (1990), onde cursou também o Mestrado e o Doutorado em Letras. Concluiu o Mestrado em 1999 e o Doutorado em 2004. Fez Pós-Doutorado na Faculdade de Ciências e Letras, Unesp/ Araraquara, 2015-2016. É docente e pesquisadora em RDIDP na Faculdade de Ciências e Tecnologia/Unesp, câmpus de Presidente Prudente. Atua no Departamento de Educação e no Programa de Pós-Graduação em Educação. Tem experiência na área de Letras, com ênfase no ensino de Língua Portuguesa. Sua pesquisa está concentrada principalmente nos seguintes temas: linguística, ensino da língua portuguesa, produção de texto, ensino de ortografia, leitura e formação do professor. É líder do Grupo de Pesquisa "Formação de Professores e Práticas de Ensino na Educação Básica e Superior"

2 Possui graduação em Direito pela Universidade Estadual de Londrina (2005). Pós-graduada em Docência no Ensino Técnico e Superior pelo Centro Universitário Toledo de Araçatuba (2014). Mestre (2017) e Doutoranda (2018-2022) na área da Educação pela UNESP - Campus de Presidente Prudente, na Linha de Pesquisa "Processos Formativos, Ensino e Aprendizagem". Participa do Grupo de Pesquisa "Formação de Professores e Práticas de Ensino na Educação Básica e Superior" da UNESP - Presidente Prudente, liderado pelas professoras Ana Luzia Videira Parisotto e Renata Portela Rinaldi. Atualmente é bolsista pela Capes e se interessa por estudos e pesquisas na área de Letramento Acadêmico, Escrita no Ensino Superior, Formação de Professores do Ensino Superior, Práticas Pedagógicas e Processos de Aprendizagem e Ensino. Membro afiliado (Amiga da Rede) à Rede Nacional de Ciência para Educação. 
jovens, solteiros, advindos da escola pública e sustentados pela família. seus pais, em sua maioria, concluíram no máximo o ensino fundamental. o principal meio de acesso à informação desses estudantes é a internet, utilizada principalmente para pesquisas e lazer (bate-papos, redes sociais, jogos ou vídeos). outro aspecto que ficou bastante claro é que tanto o perfil leitor como o escritor se consolidaram em experiências positivas na infância, seja por estímulo de familiares ou da escola. considerar a relação entre os perfis apresentados pode ser determinante para a formação de um futuro professor com bom nível cultural, que seja um mediador de leitura e escrita.

Palavras-chave: Formação Inicial do Professor. Perfil dos Alunos. Curso de Pedagogia.

Abstract: It is important that student teachers be open to becoming teachers from the very beginning of undergraduate studies, which in turn should provide them with formative experiences that promote the development of practical professional knowledge, as this is the proper time to build the basis for future professional expertise. From this perspective, this article aims to describe and analyze the socioeconomic-cultural, reading and writing profile of students that entered the Pedagogy program in 2017 by means of a questionnaire. The participants in this qualitative research of a descriptive-analytic nature are 79 student teachers: 36 from the afternoon shift and 43 from the evening shift of the program. The results indicate that the students are mostly female, young adults, single, public school graduates, and financially dependent on their families. Most of their parents have only completed elementary school. Their chief information source is the Internet, which is mainly used for leisure (chatrooms, social networks, games or videos) and research purposes. Moreover, their reading and writing profile was established during childhood, motivated by either their families or their schools. Getting to know their profiles is fundamental to crafting the education of well-rounded teachers capable of facilitating reading and writing.

Key words: Initial Teacher Education. Student Profile. Pedagogy.

Resumen: Es importante que la apertura para transformarse en profesor sea iniciada aún en el pre-grado que debe propiciar experiencias formativas que posibiliten el desarrollo de conocimientos necesarios a la práctica profesional, pues es el momento de construirse una base para el desempeño profesional futuro. En esa perspectiva, el objetivo del presente artículo es describir y analisar el perfil socioeconómico-cultural, de lectura y escritura del alumno ingresante al curso de Pedagogia, en 2017, por medio de la aplicación de un cuestionario. La investigación es de abordaje cualitativa, de carácter descriptivo-analítico, cuya muestra contó con 79 estudiantes: 36 del turno de dia e 43 del periodo nocturno. Los datos apuntan que los alumnos del curso de Pedagogia son predominantemente del sexo femenino, jóvenes, solteros, provenientes de escuelas públicas y sustentados por su família. Sus padres, en la mayoria, concluyeron máximo la enseñanza primaria. El principal medio de acceso a la información de estos estudiantes es el internet, utilizada principalmente para investigación y distracciones (conversaciones, redes sociales, juegos o videos). Otro aspecto que quedo bastante claro es que tanto el perfil del lector como del escritor se consolidan en experiencias positivas en la infancia, sea por estímulo de familiares o de la escuela. Considerar la relación entre los perfiles presentados puede ser determinante para la formación de un futuro profesor com buen nivel cultural, que sea un mediador de lectura y escritura.

Palabras claves: Formación Inicial del Profesor. Perfil de los Alumnos. Curso de Pedagogia.

\section{INTRODUÇÃO}

No Brasil, os cursos para preparar docentes para o ensino das "primeiras letras" remontam do final do século XIX com a criação das Escolas Normais (GATTI, 2010). A partir de então, a preocupação com a formação educacional da população brasileira aumentou, perpassando diferentes contextos sociais e políticos, culminando com a criação da Lei de Diretrizes e Bases da Educação Nacional (LDB) em 1996, as Diretrizes Curriculares Nacionais para 
a Formação de Professores em 2002, além das Diretrizes Curriculares para cada licenciatura que passaram a ser aprovadas pelo Conselho Nacional de Educação nos anos seguintes.

No que tange ao curso de Pedagogia,

[...] somente em 2006, depois de muitos debates, o Conselho Nacional de Educação aprovou a Resolução n. 1, de 15/05/2006, com as Diretrizes Curriculares Nacionais para esses cursos, propondo-os como licenciatura e atribuindo a estes a formação de professores para a educação infantil e anos iniciais do ensino fundamental, bem como para o ensino médio na modalidade Normal, onde fosse necessário e onde esses cursos existissem, e para a educação de jovens e adultos, além da formação de gestores. Essa licenciatura passa a ter amplas atribuições, embora tenha como eixo a formação de docentes para os anos iniciais da escolarização. (GATTI, 2010, p. 1357).

Tendo por base as atribuições do pedagogo elencadas na Resolução $n^{\circ} 1$, de 15/05/2006, não se pode olvidar que o papel desempenhado pelos futuros professores é de extrema importância, pois serão os primeiros mestres a atuarem na formação de cidadãos conscientes de seu papel em nossa sociedade.

Em sua formação, o professor não está submetido somente ao saber teórico adquirido ao longo da graduação, pois seu currículo oculto já traz experiências e vivências próprias, de dentro da família, dos níveis de ensino precedentes, os quais acabarão por impactar a sua formação, bem como sua atuação no processo de ensino-aprendizagem. Essas características não devem ser desprezadas, "[...] uma vez que estas têm peso sobre as aprendizagens e seus desdobramentos na atuação profissional" (GATTI, 2010, p. 1361).

Conforme explica Fernandez (2010, p. 4):

Na perspectiva do papel docente dentro da escola, o professor é visto como o responsável pela transmissão da cultura - o saber, o pensar, o ser e a ideologia. Ele tem o poder de influenciar as atitudes, percepções e de perpetuá-las ou contrapô-las ao longo da história. Assim como os alunos que ensina, o professor tem a oportunidade, em suas aprendizagens e reflexões, de se distanciar da cultura que o socializou e percebê-la criticamente. Nestas aprendizagens, ele pode atuar como mestre crítico-intérprete e auxiliar seus alunos no conhecimento de forma reflexiva, crítica e histórica. O professor ocupa uma posição diferenciada nas relações sociais, que exige da formação uma meIhor compreensão do seu ofício e das expectativas em relação à sua atuação.

A formação de professores é um instrumento importante para a transformação social. Um cidadão, em algum momento da sua vida, pode passar pelas mãos do professor e carregar consigo um pouco do seu jeito, seu conhecimento e sua visão de mundo. $A$ responsabilidade é grande. No ensino superior isso se evidencia na prática profissional do aluno, na transformação social e no compromisso com a humanidade.

Diante desse cenário, interessa-nos refletir sobre a formação docente inicial de alunos de um curso de Pedagogia, oferecido em uma universidade estadual, no interior do Estado de 
São Paulo. Nessa perspectiva, nosso objetivo para o presente artigo é descrever e analisar o perfil o perfil socioeconômico-cultural, de leitura e de escrita do aluno ingressante no curso de Pedagogia por meio da aplicação de um questionário.

\section{PONTO DE PARTIDA: COM QUEM COMPARTILHAMOS SABERES SOBRE FOR- MAÇÃO DOCENTE E ENSINO DE LÍNGUA MATERNA}

Nas palavras de Demo (2009, p. 89), mais do que nunca, o professor assume um papel de suma importância para mudanças sociais, uma vez que "precisa formar-se adequadamente na origem e manter-se atualizado de maneira permanente. [...] Este professor tem em suas mãos a instrumentação mais sensível de mudança, se souber trabalhar bem o lado disruptivo do conhecimento. Sua missão é inventar um povo que saiba pensar".

Assim, Schwab (1983, p. 245) reforça a ideia de que o trabalho desenvolvido pelos professores é uma arte. Cada uma das escolhas que devem ser tomadas ao longo do dia são motivadas por circunstâncias únicas, para um certo grupo de alunos e demandam um ritmo próprio. Assim, são considerados artistas por terem que frequentemente tomar decisões instantâneas diante de cada situação apresentada, continuamente.

A relevância do processo de ensino-aprendizagem também é destacada por Feiman-Nemser (1989, p. 28), que diferencia o ensino de outros serviços humanos por preocupar-se em ajudar os alunos a aprenderem coisas valiosas que não seriam capazes de aprender sozinhos.

Acreditamos na importância de que a abertura para o transformar-se em professor seja iniciada ainda na graduação que deve propiciar experiências formativas que possibilitem o desenvolvimento de conhecimentos necessários à prática profissional, pois é o momento de se construir uma base para o desempenho profissional futuro. Embora a formação inicial não consiga contemplar uma formação completa e definitiva, o que seria até incoerente se pensarmos que o professor atua num espaço carregado de imprevisibilidade, é na licenciatura que o futuro professor deve adquirir conhecimentos que vão formar seus quadros referenciais para o desempenho da profissão docente (MIZUKAMI, 1996).

Acreditamos ainda que o professor é peça chave para estimular a leitura e a escrita dos alunos, porém é preciso ser leitor/escritor, senão dificilmente conseguirá motivar e estimular os estudantes para o exercício de práticas significativas de interação verbal.

Todavia, o quadro educacional brasileiro revela uma realidade preocupante:

[...] no que se refere ao básico dos básicos que é o domínio da leitura e da escrita, ainda não conseguimos superar a produção do analfabetismo, mantendo uma vergonhosa produção de analfabetos, condenados que ficamos, mesmo na América Latina, a uma posição desconfortável de não conseguir que todas as crianças brasileiras possam dominar a leitura e a escrita. Pois é a partir daí, do saber ler e escrever que, no decorrer da escolaridade obrigatória e para além dela, os estudantes irão se apropriando dos conhecimentos que lhes possibilitem mudar as próprias vidas e mudar o mundo. (GARCIA, 2011, p. 9) 
Desta forma, indicadores e pesquisas nacionais já constataram que crianças avançam do Ensino Fundamental I com enormes dificuldades de leitura e escrita, jovens concluem o ensino médio sem ao menos saber escrever uma boa redação ou interpretar textos, o que evidencia o fracasso escolar (ESTEBAN, 2013; SOARES, 2003; WEISS, 2002). A situação se agravou de tal forma que já atingiu o ensino superior, onde já encontramos alunos com sérias deficiências em leitura e escrita.

Em contrapartida, seria esperado que aquele que ingressa no ensino superior, após tantos anos em contato com a língua materna, saiba dominá-la, conforme expõe Velásquez (2012, p. 02):

Da clientela que entra no ensino superior espera-se que seu alfabetismo funcional/letramento se encontre em um nível pleno, ou seja, possuam habilidades que não colocam restrições para compreender e interpretar textos. Leem textos mais complexos, conseguindo fazer inferências e deduções. Além de fazer ligações, comparações e avaliações sobre o conteúdo textual, independente do gênero.

O pouco incentivo à leitura e as restritas e descontextualizadas oportunidades de produção textual em todos os níveis de ensino têm causado impactos e consequências negativas na formação de leitores e escritores, até mesmo nas graduações.

Logo, no que tange aos problemas de leitura e de produção de textos escritos,

É fato que tais dificuldades não deveriam mais estar presentes nos alunos do Ensino Médio e Superior, mas o que se percebe é que, cada vez mais, esses têm demonstrado deficiências bastante significativas nessas habilidades essenciais para um bom desempenho profissional, intelectual e social; requisitos fundamentais para o pleno exercício da cidadania, exigência da sociedade atual. (GREGÓRIO, 2006, p. 77).

Esse cenário se mostra bastante alarmante: ao mesmo tempo em que muitos graduandos que serão futuros professores possuem deficiência em leitura e escrita, é bastante provável que essa defasagem tenha um impacto negativo na formação de novos leitores e escritores.

Por outro lado, além da falta de estímulo e da má-formação das competências leitora e escritora nos níveis precedentes, o ensino superior também apresenta um alunado resistente a escrever e com muitas limitações para exercitar a escrita: muitos alunos têm o que dizer, mas não sabem como fazê-lo; falta de tempo para praticar e exercitar a escrita; desmotivação, já que muitos alunos não concebem a escrita como oportunidade de se colocar no mundo, de se entender e entender a realidade; excesso de preocupação em escrever bem, ao invés de escrever com clareza (VITÓRIA, 2011).

Quando o aluno sai do Ensino Médio e ingressa no Ensino Superior, geralmente, apresenta grandes dificuldades para acompanhar as exigências de leitura e de escrita, pois sua trajetória, nas etapas anteriores de ensino, não visou ao letramento, ou seja, não formou o sujeito discursivo. Assim, a escola tem formado alunos, mas não sujeitos que extrapolam conteúdos e assumem o papel de produtores de texto. Desta forma, "o ensino 
que é voltado para a interação verbal, proporciona aos alunos condições e possibilidades de se constituírem como sujeitos, que organizam seus enunciados na interação com outros sujeitos nas relações cotidianas" (LUZZI, 2014, p. 632).

\section{DELINEANDO O PERCURSO DA PESQUISA}

Considerando como objeto de estudo o perfil socioeconômico-cultural, leitor e escritor dos alunos ingressantes no curso de Pedagogia, desenvolvemos uma pesquisa qualitativa, de caráter descritivo-analítico (GODOY, 1995), em uma instituição de ensino superior pública do interior paulista.

Ainda que as pesquisas na área de ciências sociais sejam marcadas por métodos quantitativos na descrição e explicação dos fenômenos investigados, optamos pela abordagem qualitativa para explicar em profundidade as características e os significados das informações obtidas (OLIVEIRA, 2007).

Também, elegemos o enfoque descritivo-analítico, pois, conforme Martins (2008, p. 56), "o mérito principal de uma descrição não é sempre sua exatidão ou seus pormenores, mas a capacidade que ela possa ter de criar uma reprodução tão clara quanto possível para o leitor da descrição".

Foram sujeitos de nossa pesquisa os alunos do primeiro semestre do curso de Pedagogia, visto que nossa intenção foi traçar o perfil do futuro professor ingressante no ensino superior, em 2017. Empreendemos esforços para delinear sua competência leitora e escritora, visto que o exercício da profissão docente demanda essas competências. Também, julgamos indispensável conhecer o perfil socioeconômico-cultural do aluno, visto que possivelmente impactará na formação docente.

A amostra foi composta por 79 estudantes: 36 do turno vespertino e 43 do período noturno. A participação foi facultada aos interessados em colaborar na pesquisa, havendo adesão total.

O instrumento que utilizamos foi o questionário, por ser uma "técnica de investigação composta por um número mais ou menos elevado de questões apresentadas por escrito às pessoas, tendo por objetivo o conhecimento de opiniões, crenças, sentimentos, interesses, expectativas, situações vivenciadas etc." (GIL, 2008, p. 121).

O questionário foi formulado para situar os alunos do ponto de vista socioeconômico-cultural e conhecer seu perfil de leitura e de escrita. Apresenta duas seções: a) a primeira levantou questões relativas ao perfil socioeconômico-cultural, com uma questão aberta e todas as demais fechadas; b) a segunda traçou o perfil leitor e escritor dos investigados, com questões mistas (requerem justificativa sobre a alternativa escolhida).

Os dados foram organizados, tabulados, categorizados a posteriori e analisados à luz da análise de conteúdo (BARDIN, 2011; FRANCO, 2008), bem como do referencial teórico voltado para formação docente e ensino de língua materna (LERNER, 2002; VELÁSQUEZ, 2012; GATTI, 2010; FERNANDEZ, 2010; LUZZI, 2014; SOARES, 2003). 
A coleta de dados foi concretizada no primeiro semestre do ano de 2017. Omitimos os nomes dos alunos, bem como o da instituição investigada. Optamos, então, por identificá-los por uma combinação alfanumérica, na qual a letra $V$ designa os alunos do vespertino e a letra $\mathrm{N}$ os alunos do noturno. Os números cardinais, de 01 até o número máximo de investigados em cada turno, representam os alunos, de forma aleatória. Assim, a combinação V01, por exemplo, representa o primeiro aluno analisado do turno vespertino, ao passo que a combinação N07 se refere ao sétimo aluno investigado do noturno.

Ressaltamos que, apesar de os dados dos alunos dos turnos vespertino e noturno terem sido analisados separadamente, não notamos diferenças que justifiquem uma distinção entre os períodos, na apresentação dos resultados. Dessa forma, apresentaremos a análise dos dados englobando todos os sujeitos pesquisados sem distinção de turno de curso.

\section{OS CENÁRIOS DESVELADOS E ANALISADOS}

Com relação aos resultados relativos ao perfil socioeconômico-cultural, optamos por apresentá-los na forma de gráficos, acompanhados de pequenas tabelas.

Já com relação ao perfil de leitura e escrita dos investigados, nossa opção foi pela transcrição das respostas, a fim de trazer, com mais riqueza de detalhes, a voz do sujeito pesquisado.

Passemos, portanto, aos resultados que obtivemos.

\subsection{PERFIL SOCIOECONÔMICO-CULTURAL DOS INVESTIGADOS}

Analisemos o Gráfico 1, o qual mostra o sexo dos investigados.

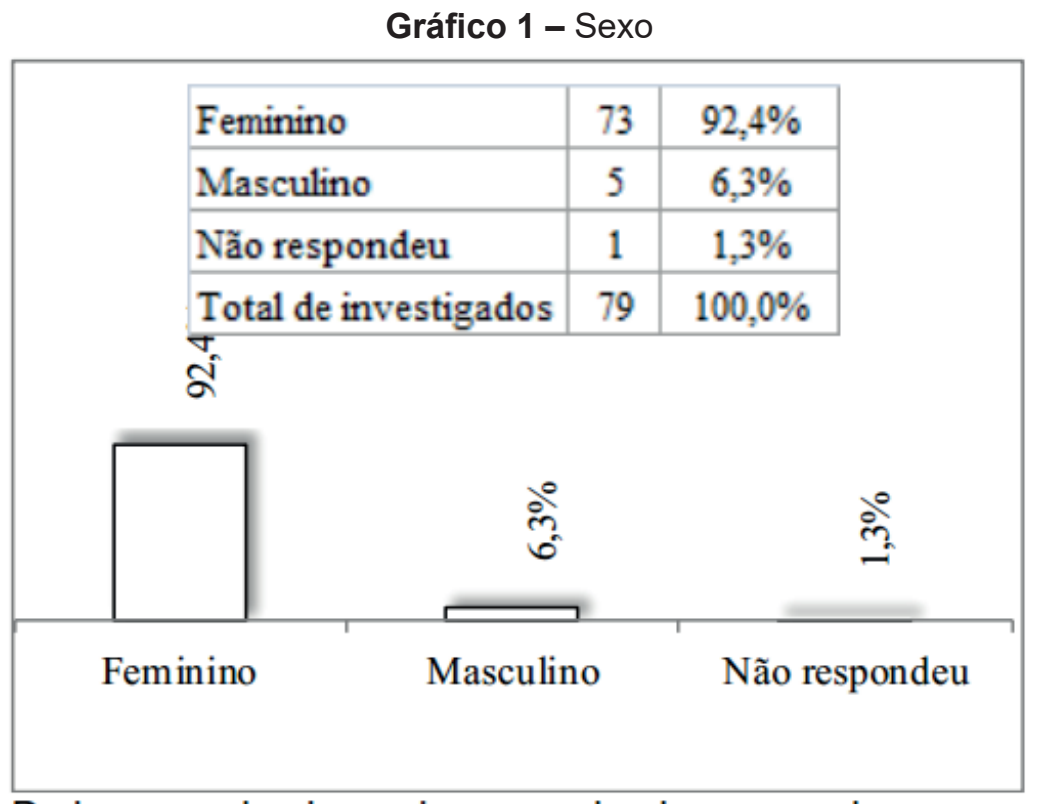

Fonte: Dados organizados pelas pesquisadoras com base nos resultados (2018) 
Os dados colhidos demonstram que a maioria dos alunos do curso de Pedagogia é do sexo feminino, reafirmando as pesquisas que constatam a feminização desta graduação. Esse processo se iniciou com a expansão das Escolas Normais, no final do século XIX, momento,

[...] em que a mulher era "destinada" às tarefas domésticas e educativas. Assim, a docência era aceita como uma das poucas atividades extradomésticas adequadas para as mulheres, sendo vista até mesmo como uma preparação para o casamento. (GUTIERRES et al., 2012).

A feminização é um fenômeno considerado biológico que se pauta na ideia de vocação para atividades maternas. Construiu-se uma imagem de que as mulheres possuem características específicas para atuar no magistério. A sociedade, e a própria escola, reforçaram a manutenção desse modelo tradicional de feminilidade, o qual persiste até hoje. Aliás, a maior parte dessas mulheres irá atuar principalmente na educação infantil e no ensino fundamental (FERREIRA; CARVALHO, 2006).

Passemos à análise da faixa etária (Gráfico 2) e do estado civil (Gráfico 3 ) em nossa pesquisa.

Gráfico 2 - Faixa

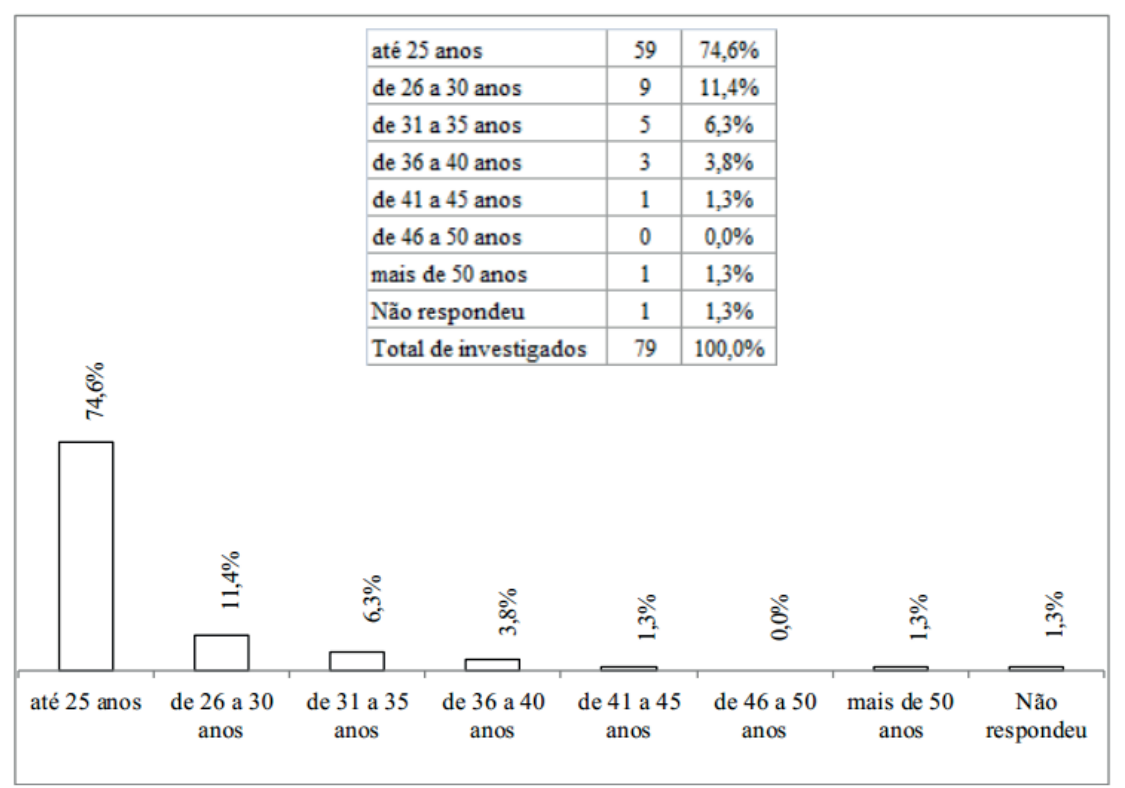

Fonte: Dados organizados pelas pesquisadoras com base nos resultados (2018) 
Gráfico 3 - Estado civil - Amostra do interior do estado de São Paulo - 2018

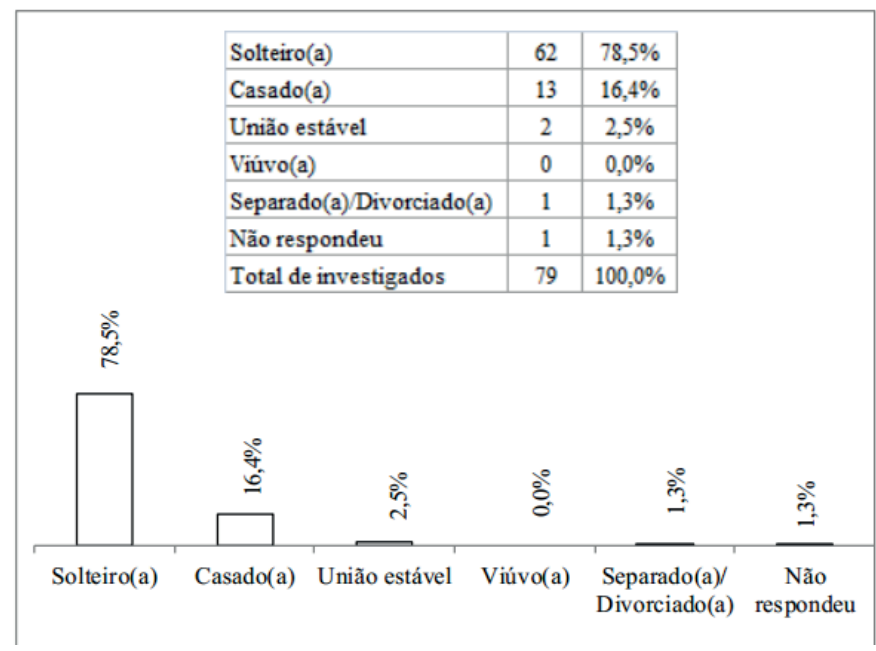

Fonte: Dados organizados pelas pesquisadoras com base nos resultados (2018)

O Gráfico 2 demonstra que os investigados são, em sua maioria jovens, visto que $74,6 \%$ possuem até 25 anos. Já o Gráfico 3 evidencia que os formandos são eminentemente solteiros, representando $78,5 \%$ da amostra. Ressalte-se que os graduandos com mais idade são aqueles que apresentam estado civil de casado(a) ou união estável.

Além disso, por se tratar de um público majoritariamente feminino, constatamos que os dados retratam bem a realidade da mulher na sociedade contemporânea: "[...] adiamento da nupcialidade e da maternidade com vistas na construção de uma carreira profissional para melhor qualificação no mundo do trabalho" (GUTIERRES et al., 2012, p. 4).

Na sequência, o Gráfico 4 nos auxilia a traçar o perfil dos investigados quanto aos precedentes escolares.

Gráfico 4 - Escola em que cursou o Ensino Fundamental e Médio

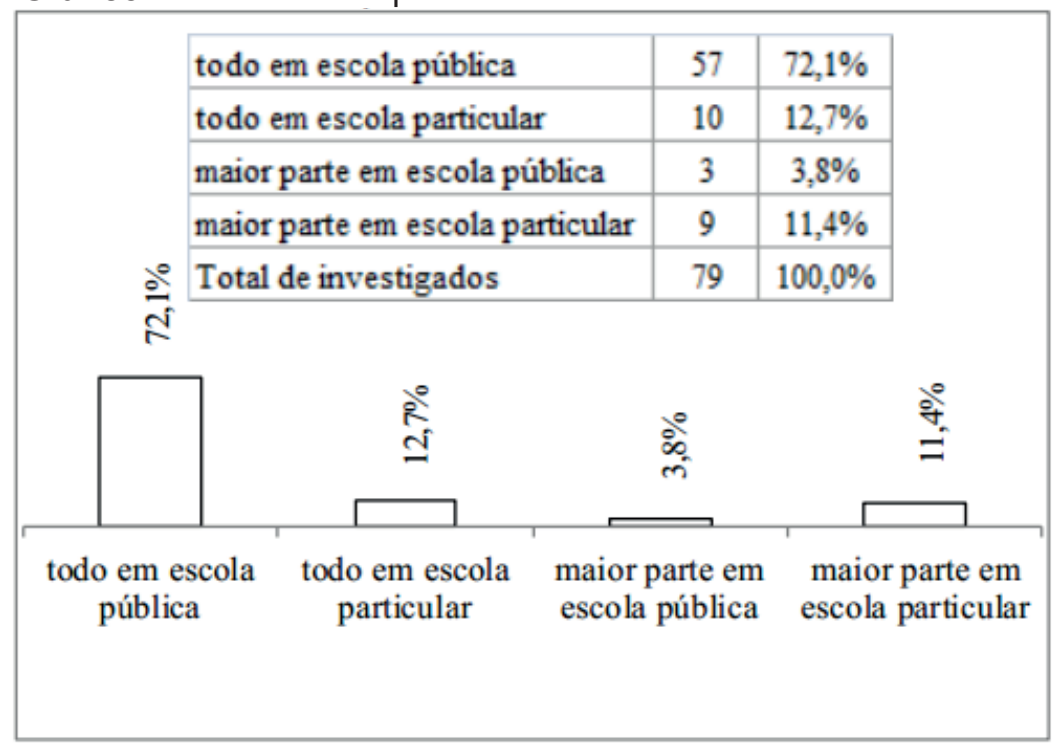

Fonte: Dados organizados pelas pesquisadoras com base nos resultados (2018) 
Assim, aferimos que os investigados são oriundos, em sua maioria, da escola pública: $72,1 \%$ dos alunos cursaram o Ensino Fundamental e Médio todo em escola pública, e $3,8 \%$ o cursaram em sua maior parte em escola pública. Este quadro revela que o curso de Pedagogia do ensino superior público, de forma geral, é composto por um alunado advindo do ensino público.

Indiretamente, esses resultados deixam transparecer um poder aquisitivo menor da maioria dos investigados, que não pode investir em ensino privado. Neste sentido, explica-nos Silva (2001, p. 297):

A superioridade da situação sócio-econômica se traduz, neste caso, por melhores condições de preparo para o vestibular: bons colégios, o que no nosso contexto significa colégios e cursinhos caros, existindo aí o entrecruzamento do aluno melhor preparado com o aluno que dispõe de condições sócio-econômicas para atingir este nível. [...] O que esta situação revela não é a substituição do mérito pela condição sócio-econômica, mas sim que aqueles que dispõem de meios estão mais aptos a cumprir os requisitos de mérito.

Por outro lado, frequentar uma escola pública ou particular não deveria impactar o desempenho dos estudantes. Todavia, o que vislumbramos é que a educação privada tem obtido um pouco mais de êxito, inclusive com relação à formação da competência leitora e escritora dos alunos. Some-se a isso, o fato de os alunos com um maior poder aquisitivo se sentirem desmotivados a cursarem carreiras voltadas à licenciatura, uma vez que são tidas como carreiras desprestigiadas e sem retorno financeiro motivador. Tal fato, inclusive, justifica o alto percentual de investigados originário da educação pública.

Assim, "a escolaridade anterior realizada em escola pública evidencia grandes carências nos domínios de conhecimentos básicos. É com esse cabedal que a maioria dos licenciandos adentra nos cursos de formação de professores." (GATTI, 2010, p. 1364-1365).

O nível de instrução familiar dos investigados mostrou-se diversificado: apenas $11,4 \%$ dos pais e $20,2 \%$ das mães possuem Ensino Superior completo, conforme ratifica o Gráfico 5: 
Gráfico 5 - Escolaridade dos pais

\begin{tabular}{|l|c|c|l|c|c|}
\hline \multicolumn{2}{|c|}{ Pai } & \multicolumn{4}{c|}{ Mãe } \\
\hline Não frequentou a escola & 1 & $1,3 \%$ & Não frequentou a escola & 1 & $1,3 \%$ \\
\hline Nivel fundamental incompleto & 25 & $31,6 \%$ & Nivel fundamental incompleto & 21 & $26,6 \%$ \\
\hline Nivel fundamental completo & 13 & $16,5 \%$ & Nivel fundamental completo & 6 & $7,6 \%$ \\
\hline Nivel médio incompleto & 6 & $7,6 \%$ & Nivel médio incompleto & 5 & $6,3 \%$ \\
\hline Nivel médio completo & 19 & $24,0 \%$ & Nivel médio completo & 24 & $30,4 \%$ \\
\hline Nivel superior incompleto & 4 & $5,10 \%$ & Nivel superior incompleto & 6 & $7,6 \%$ \\
\hline Nivel superior completo & 9 & $11,40 \%$ & Nivel superior completo & 16 & $20,2 \%$ \\
\hline Não respondeu & 2 & $2,50 \%$ & Não respondeu & 0 & $0,0 \%$ \\
\hline Total de investigados & 79 & $100,0 \%$ & Total de investigados & 79 & $100,0 \%$ \\
\hline
\end{tabular}

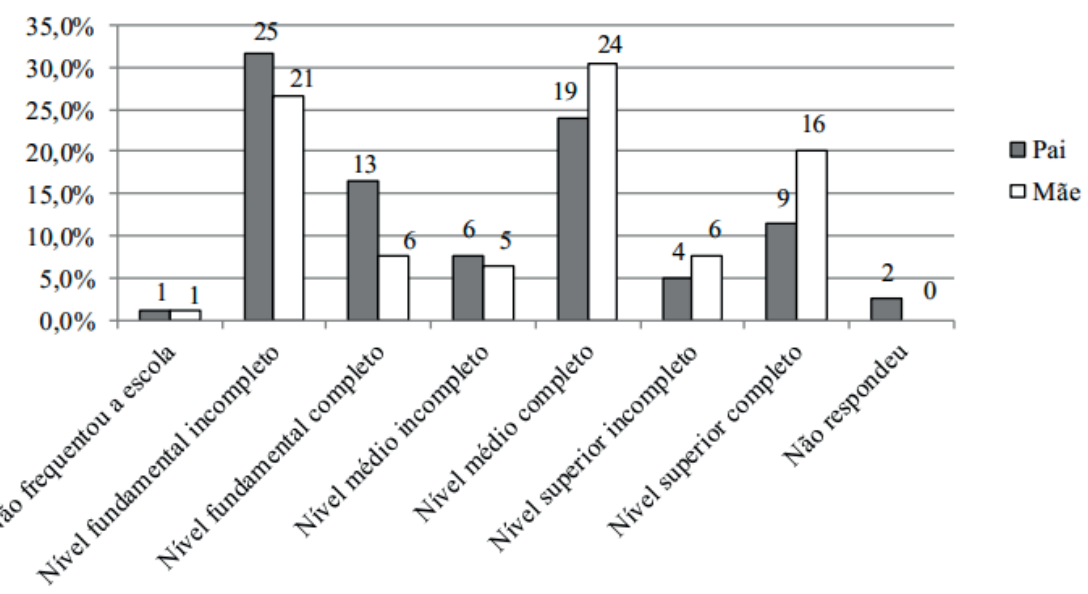

Fonte: Dados organizados pelas pesquisadoras com base nos resultados (2018)

Ressalte-se que "escolaridade dos pais pode ser tomada como um indicador importante da bagagem cultural das famílias de que provêm os estudantes" (GATTI, 2010, p. 1363). É notório que o fato de uma pessoa concluir uma graduação lhe possibilita ocupar cargos mais bem remunerados do que a de escolaridade mais baixa, com uma realidade otimizada pelos recursos materiais e sociais. Também, é comum que aqueles que tiveram a oportunidade de concluir uma graduação valorizem o ensino e se sintam preocupados com a crise da educação pública brasileira. Portanto, é bastante corriqueiro encontrarmos pais com ensino superior completo que busquem escola particular para seus filhos, quer seja pela melhor condição financeira proporcionada pela formação em que investiu, quer seja pela realidade preocupante do ensino público, ou mesmo por ambas as opções.

A regra é que "pais e mães dos estudantes de Pedagogia são sistematicamente menos escolarizados que os dos demais cursos" (GATTI, 2012, p. 1364). Porém, se levarmos em conta que pelo menos $30 \%$ dos genitores estão em duas categorias de baixa instrução escolar - nunca frequentaram a escola ou cursaram no máximo o nível fundamental -, há um claro processo de ascensão dos filhos que alcançaram o curso de Pedagogia.

Mais um aspecto que investigamos foi a participação dos sujeitos na vida econômica da família, conforme se verifica no Gráfico 6. 
Gráfico 6 - Participação na vida econômica da família

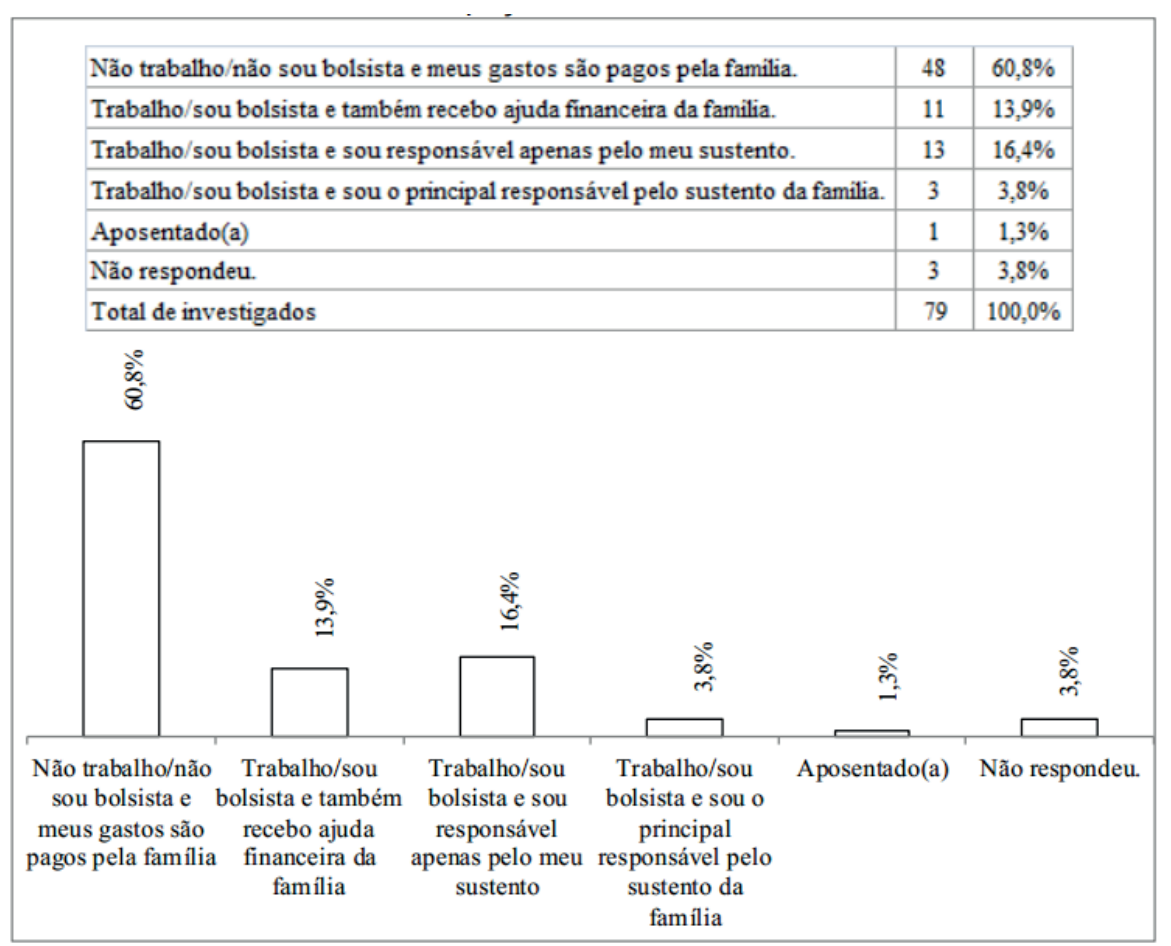

Fonte: Dados organizados pelas pesquisadoras com base nos resultados (2018)

Entre os investigados, predomina o alunado que não trabalha/ não é bolsista e tem seus gastos pagos pela família, com uma margem percentual de $60,8 \%$, o que coincide com o público jovem e solteiro predominante na sala de aula.

Retomando os Gráficos 2 e 3 sob o prisma do Gráfico 6, importante ressaltar que os alunos com mais idade são casados(as) ou vivem união estável, além de grande parte assumir posição economicamente ativa na família de provedores do lar. Em contrapartida, os jovens solteiros podem se dedicar melhor aos estudos, pois não possuem a responsabilidade de manter economicamente uma família.

Passamos, assim, às análises dos gráficos seguintes (Gráficos 7 e 8) que certamente trazem dados para nos auxiliar a entender a visão de mundo dos investigados e quais as suas fontes de leitura e de argumentos: 
Gráfico 7 - Frequência de leitura de jornal

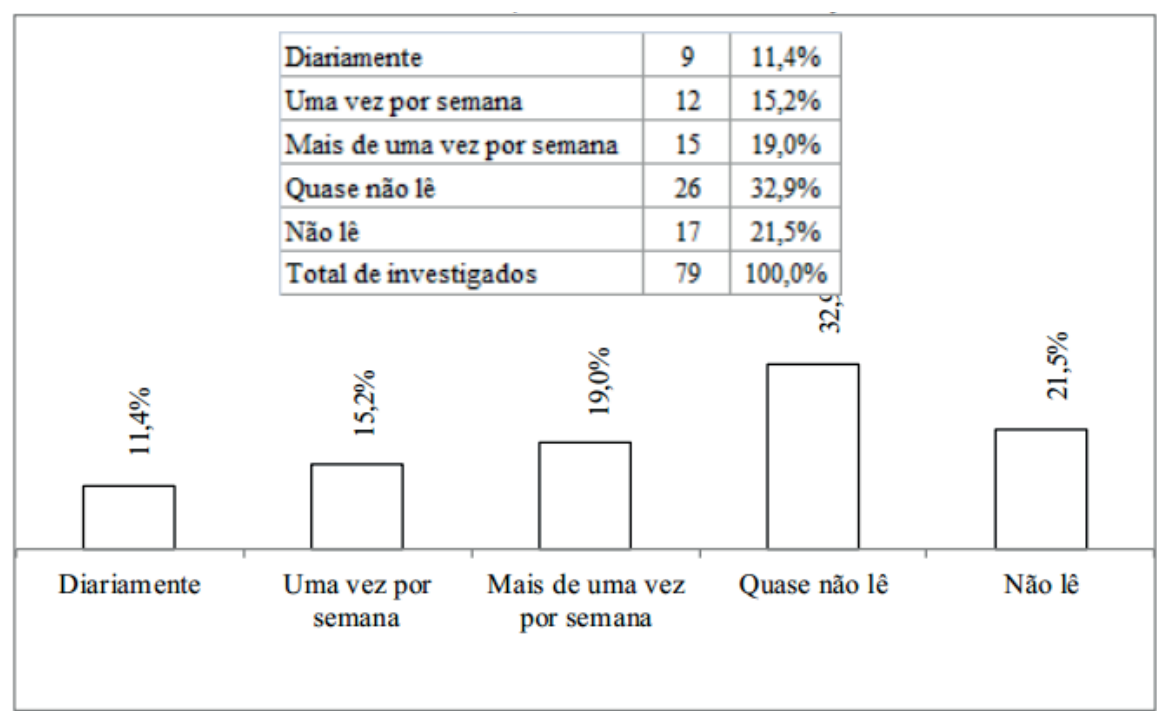

Fonte: Dados organizados pelas pesquisadoras com base nos resultados (2018)

O interesse por leitura de jornais (mesmo online) é pequeno, já que as categorias "quase não leem" e "não leem" representam mais da metade dos investigados.

O Gráfico 8, apresentado na sequência, revela dados sobre o uso da internet, bem como acerca da leitura de jornal (inclusive online) pelos alunos.

Gráfico 8 - Tempo utilizado para assistir a programas televisivos e tempo utilizado para acessar à internet

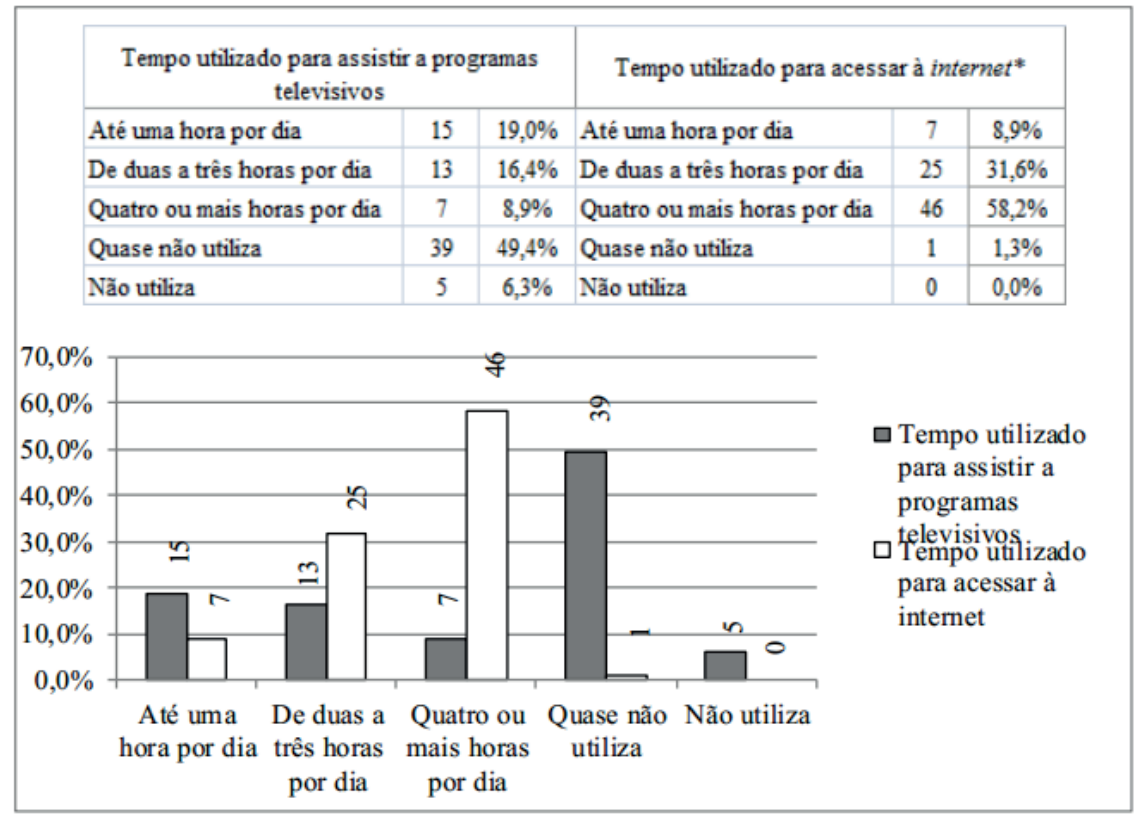

Fonte: Dados organizados pelas pesquisadoras com base nos resultados (2018)

Nota: * Engloba qualquer meio com acesso à internet (computador, notebook, tablet, smartphone). 
Notamos que os investigados são pouco interessados por assistir televisão: 49,4\% do montante não assistem e 6,3\% quase não assistem à televisão. Percebemos, portanto, que a televisão não é a principal fonte de informação dos alunos para respaldar seu conhecimento e argumentação.

Contudo, notamos que, ainda que leiam poucos jornais e não assistam à televisão, a construção dos conhecimentos dos alunos se dá pelo acesso à internet.

Logo, a internet se faz bastante presente entre os alunos para obtenção de informação e para construção do conhecimento. Constatamos que o tempo de acesso é significativo para a maioria dos alunos: $58,2 \%$ passam de quatro ou mais horas por dia conectados. Assim, elucida-nos Valente (2014, p. 145):

A Internet está ficando cada vez mais interessante, possibilitando a exploração de um número incrível de assuntos. Porém, se o aprendiz não tem um objetivo nessa busca e na sua navegação na Internet, essa atividade tem pouco significado. A navegação pode mantê-lo ocupado por um longo período de tempo, porém muito pouco pode ser realizado em termos de compreensão dos tópicos visitados. Se a informação obtida não é posta em uso, se ela não é trabalhada pelo professor, não há nenhuma maneira de estarmos seguros de que o aluno compreendeu o que está fazendo. Nesse caso, cabe ao educador suprir tais situações para que a construção do conhecimento ocorra.

Os resultados apresentados nos Gráficos 7 e 8, de certa forma, denunciam uma realidade alarmante: o Brasil não possui uma tradição de leitura, conforme esclarece Silva (2011, p. 42-43):

\begin{abstract}
Dada as condições do desenvolvimento histórico e cultural do país, a leitura, enquanto atividade de lazer e atualização, sempre se restringiu a uma minoria de indivíduos que teve acesso à educação e, portanto, ao livro. A grande massa da população, sem condições para estudar, sempre aderiu aos meios diretos de comunicação, que não exigem educação formal para sua recepção. [...] Daí também, o lazer proporcionado pela leitura ficar restrito àqueles que tiveram e que têm acesso à escola de forma privilegiada, isto é, à escola que aponta para o significado e para a referência. E como este tipo de escola não é constituído para o povo em geral, a leitura torna-se um bem ou um privilégio a ser desfrutado somente pelas elites.
\end{abstract}

Ainda sobre a internet, o Gráfico 9 revela qual o seu principal uso. 
Gráfico 9 - Principal uso da internet

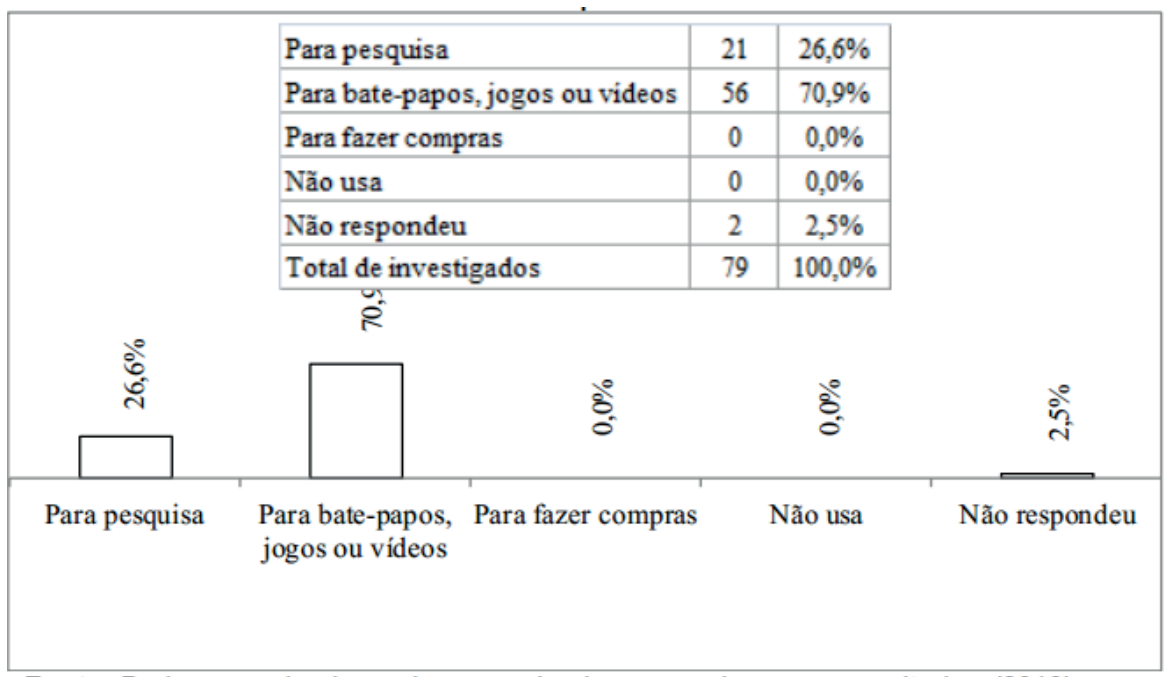

Fonte: Dados organizados pelas pesquisadoras com base nos resultados (2018)

Os dados são bastante contundentes, pois para 70,9\% dos investigados o principal uso da internet é para lazer (bate-papos, jogos, redes sociais, vídeos). Isso nos leva a questionar como esses alunos buscam o conhecimento, já que não leem jornais, e nem assistem à televisão.

Segundo constatamos, $26,6 \%$ dos alunos fazem uso da internet para a pesquisa. A internet, além de ser um meio mais econômico do que assinaturas de jornais, revistas ou de canais pagos (já que a TV aberta pouco tem a acrescer aos telespectadores), pode colaborar muito positivamente para experiências de leitura e escrita dos alunos, se bem explorada.

Ainda que a internet esteja relacionada a muitos crimes (como casos de pedofilia e cyberbullying), é um veículo muito democratizante de disseminação do conhecimento. As informações são muito fáceis de serem acessadas. A sofisticação dos aparelhos para o uso desta tecnologia é inegável. Com um simples smartphone, podemos nos conectar com o mundo e acessar uma infinidade de dados que vão além das fronteiras do nosso país.

Justamente por todas essas características, o espaço cibernético colabora para a propagação cultural, o desenvolvimento da competência comunicativa e a construção de uma sociedade globalizada. Inegável a influência do meio digital na vida escolar dos alunos, segundo aponta Kenski (2005, p. 133):

[Os alunos] aprendem em múltiplas e variadas situações. [...].

Estes alunos estão acostumados a aprender através dos sons, das cores, das imagens fixas das fotografias ou, em movimento, nos filmes e programas televisivos. [...] O mundo desses alunos é polifônico e policrômico. É cheio de cores, imagens e sons, muito distante do espaço quase que exclusivamente monótono, monofônico e monocromático que a escola costuma lhe oferecer. 
Feitas essas considerações gerais acerca do perfil socioeconômico-cultural dos alunos ingressantes no curso de Pedagogia, passaremos à análise dos perfis leitor e escritor dos investigados, a qual nos auxiliará na reflexão sobre a sua formação docente inicial.

\subsection{PERFIL LEITOR DOS INVESTIGADOS}

Questionados se a leitura era/é um hábito regular em sua vida, $74,7 \% \%$ dos sujeitos pesquisados responderam que sim. As experiências leitoras positivas remeteram principalmente ao incentivo recebido desde criança, à cobrança escolar e ao gosto pessoal por ler, conforme se verifica nos excertos a seguir:

No colégio, havia livros obrigatórios a serem lidos todo bimestre. (V20)

Desde muito pequena, quando aprendi a ler, lia desde gibis até livros mais adultos. A paixão por leitura começou na infância e se estende até atualmente. (V08)

Sim, minha familia desde pequena me influenciava a ler, principalmente minha mãe. (V13)

Sim, porque gosto muito de passar tempos de espera ou de ócio me distraindo com histórias ou notícias. Além disso, tento sempre ler com a minha filha para que ela tenha familiaridade com esse hábito (assim como minha mãe fez comigo), desenvolvendo sua fala e imaginação. (V26)

Desde pequena, fui incentivada a ler pela minha mãe, e criei o hábito de leitura. Sempre que possivel, estou lendo um livro ou texto. (N20)

Fui incentivada principalmente pela minha mãe devido a ela ser professora. Sempre gostei de ler, variando a temática. (N34)

Sempre tive um hábito à leitura, principalmente no ensino médio, quando acabei conhecendo vários livros literários que me apaixonei muito. (V14)

A leitura significa muito para mim, pois sempre que terminava um livro, tinha o costume de contar para meu pai, e era mágica essa troca que tínhamos. (N05)

Após entrar no ensino médio, o hábito tornou-se maior, por ter que fazer resumos. (N15)

Sim, por conta do projeto da escola. Eu costumava ler um livro a cada 15 dias e produzir relatos sobre minha experiência. (N42)

Notamos que as vivências denunciam que o perfil leitor é despertado desde a infância, quer seja por apoio de familiares ou professores, quer seja por outras circunstâncias que favoreçam a leitura.

Em contrapartida, 25,3\% dos investigados responderam que a leitura não é/era um hábito em sua vida. O principal motivo alegado foi a falta de incentivo (familiar e/ou escolar), a dificuldade de acesso a livros e a falta de tempo para se dedicar à leitura. A seguir, apresentamos alguns excertos: 
Tinha pouco acesso a livros por conta da rotina de vida. Morava na zona rural e necessitava ajudar em casa. (N26)

Gosto de ler livros. Porém, hoje o tempo e filhos não me permitem fazê-lo com frequência. (V34)

Depois que parei de estudar o ensino médio em 2003, não mais retornei e perdi o hábito da leitura. Os filhos também atrapalham... (V31)

\subsection{PERFIL ESCRITOR DOS INVESTIGADOS}

Questionados se a escrita era constante na vida escolar no Ensino Médio, 31,6\% responderam que não, o que corresponde a um montante significativo. A maior parte dessas respostas foram associadas a um olhar depreciativo para a escola pública (relatando que não houve cobrança de produções textuais, e nem estímulo escolar à escrita) e à falta de tempo para se dedicar aos estudos, de acordo com o que se pode verificar nos excertos a seguir:

Os professores que tive aula não costumam passar produção textual. Apenas explicar sobre as mesmas. (N01)

Poderia ter sido mais frequente. A escrita estava presente nos trabalhos bimestrais, avaliações dissertativas, textos de treinamentos (opcionais). Os textos de dissertação eram a forma de avaliação no final do $1^{\circ}$ e $2^{\circ}$ ano. (N06)

Usávamos livros onde já continham as perguntas. Era somente colocar as respostas. Eram muito raros os trabalhos. (N37)

A redação era pouco trabalhada. A professora de Língua Portuguesa enfatizava respostas curtas, objetivas. (N40)

A escola pública deixa a desejar. Pouquíssimas vezes professores pediam escrita. (N05)

Fiz o ensino médio no EJA e lá você estuda por você. (V02)

Eu estudava no período da noite e trabalhava durante o dia. Não me lembro de escrever com frequência durante o ensino médio. (V23)

Infelizmente, não foi. Tive que trabalhar muito cedo e não tive oportunidade de estudar o tanto que eu gostaria. (V36)

Durante a vida escolar na escola pública, realizei o curso durante o período noturno. Devido à realidade de boa parte dos alunos que trabalhavam, os professores não passavam quase nada em relação à produção textual. (N10)

Como vim de escola pública e rural, não escrevíamos quase nada em sala e muito menos eram pedidos trabalhos. (N35)

Todavia, $68,4 \%$ dos alunos investigados relataram que a escrita era constante em sua vida escolar no Ensino Médio, especialmente pela cobrança dos professores, com alguns relatos que enalteceram o ensino público:

Era uma forma de conhecer o aluno, testar seu conhecimento e suas práticas, mesmo não sendo frequente no ensino público. Tive várias oportunidades durante o decorrer do ensino médio de escrever. Portanto, posso dizer que a escrita foi constante. (N09) 
A cada bimestre era aplicada uma redação com um tema sugerido pela direção. Essa redação era corrigida com base nos critérios de avaliação do ENEM. Algumas vezes a professora de português também fazia o pedido de textos e corrigia em sala com os alunos. (N14)

Desde $01^{\circ}$ colegial, as respostas dissertativas eram cobradas dos alunos. As redações também fazíamos toda semana. (V08)

Durante o Ensino Médio, a aula de redação fazia parte da grade horária com duração de 100 minutos semanais, no primeiro e segundo colegial. Já no terceiro colegial, a aula era no horário oposto das aulas, com a mesma quantidade de duração. (V11)

Sim, fazia muitas dissertações na escola e no cursinho para treinamento do vestibular. (V14)

No colégio, havia redações a serem entregues toda semana. (V20)

Sim, porque as matérias sempre pediam diversos trabalhos para que os alunos pudessem se preparar para provas futuras de acesso às universidades (como o ENEM). Visar notas de redação era fundamental. (V26)

Treinei durante o ensino médio os textos com foco no vestibular. (V28)

A escrita foi constante em minha vida escolar no Ensino Médio devido às aulas de redação, provas dissertativas, redações feitas em sala de aula e outros textos produzidos durante meus estudos. (V29)

A partir do ensino médio e também no cursinho, produzi muitos textos dissertativos como forma de treinar para o vestibular. (V30)

A educação pública e de qualidade deveria ser direito de todo cidadão, porém o que vemos é a triste realidade do fracasso escolar. Dados do Ministério da Educação (MEC), por exemplo, "apontam que apenas $10 \%$ das crianças matriculadas na escola atingem o desempenho adequado nas disciplinas de Língua Portuguesa e Matemática para o nível de ensino" (LIMA; RINALDI, 2012, p. 2).

Por outro lado, não podemos culpabilizar somente a escola no fracasso de domínio leitor e escritor, pois há outros fatores intra e extraescolares capazes de influenciar no processo de ensino e de aprendizagem.

Com relação ao gosto pessoal por escrever, 68,4\% alegaram tê-lo, ao passo que $31,6 \%$ disseram que não. Lerner (2002) destaca quais são os desafios para transformar o ensino da escrita, vários dos quais entendemos também se fazerem presentes nas graduações: formar praticantes da escrita, e não apenas operadores do sistema de escrita; orientar ações para a formação de escritores, de pessoas que se comuniquem por escrito, ao invés de continuar formando sujeitos ágrafos, os quais utilizam a escrita somente como último recurso; formar alunos produtores de língua escrita, conscientes da pertinência e importância de emitir certo tipo de mensagem em determinado tipo de situação social, em vez de treinar meros reprodutores; deixar de se ter a escrita na escola somente como um objeto de avaliação, para se constituir em um objeto de ensino; utilizar a escrita como instrumento de reflexão sobre o próprio pensamento, como recurso para organizar e reorganizar o próprio conhecimento, distanciando-se da ideia que a escrita é meio para reproduzir ou resumir o pensamento dos outros. 
Tendo por base os desafios propostos por Lerner (2002), salientamos as principais críticas daqueles que não possuem gosto pela escrita, estando relacionadas à falta de estímulo no ambiente escolar e fora dele (já constatamos que há grande influência de desenvolvimento da competência leitora e escritora na infância) e à preferência pela leitura. $\mathrm{A}$ título de exemplo, trouxemos alguns excertos:

Nunca fui estimulada a escrever. (V06)

Não houve um incentivo maior pela escrita. (V22)

Desde pequeno, não fui influenciado por minha mãe. (N24)

Gosto mais de leitura. (V17)

Gosto mais de ler. Fui pouco incentivada a escrever. (V32)

Gosto mais de ler. A literatura era a única matéria dentro da língua portuguesa que me interessava. (NO6)

Não tenho costume de escrever, a não ser o necessário (escola, trabalho, cursinho, faculdade etc.). (V30)

Em contrapartida, várias experiências positivas pelo gosto especial de escrever foram mencionadas, a maioria relacionada à influência familiar e à satisfação pessoal:

Tenho paixão pelo português e pensei em seguir a área de Comunicação. A vontade de escrever e propagar ideias sempre foi muito forte em mim. (V08)

Sempre gostei de escrever. Antes eu gostava mais de poemas/poesias; agora gosto de textos de artigo de opinião, até porque foi um gênero que na escola trabalhou-se bastante. (V13)

Gostava de escrever músicas na época do colegial. (V18)

Gostava muito de produzir textos literários ou dissertativos como hobby porque minha mãe também gostava. Isso acabou me influenciando muito. (V26)

Devido à influência da minha irmã que cursou Letras, aprendi a ler posteriormente, a praticar a escrita. No primeiro momento, durante o processo de escolha do primeiro curso de graduação, almejava cursar Letras. (N10)

Participei de congressos da rede estadual onde os alunos expõem seus próprios textos literários. Interesso-me por crônicas (já escrevi para professores da rede estadual) e poemas (expostos em sarau na escola). (V28)

Algumas vezes, produção de poemas e versos. (V33)

Sempre tive interesse por escrita, desde o ensino fundamental, principalmente com produção de redações. No ensino médio, de forma pessoal, fui aumentando minhas produções de textos, incluindo poesias e contos, chegando a escrever num blog pessoal (que hoje não existe mais). (N12)

Sim, sempre tive gosto. Inclusive ganhei premiação de melhor redação. (N38)

Adoro escrever contos e reescrita de contos mitológicos. (N42)

\section{CONSIDERAÇÕES FINAIS}

O professor desenvolve um papel extremamente importante dentro de uma sociedade. Todos, independentemente da profissão escolhida, passarão pelas mãos de um mestre. 
Dessa forma, é muito importante refletirmos sobre o perfil socioeconômico-cultural dos estudantes de Pedagogia em formação, principalmente para se repensar o currículo do curso e discutir a identidade docente.

Os dados apontam que os alunos do curso de Pedagogia são predominantemente do sexo feminino, jovens, solteiros, advindos da escola pública e sustentados pela família. Seus pais, em sua maioria, concluíram no máximo o ensino fundamental. O principal meio de acesso à informação desses estudantes é a internet, utilizada principalmente para pesquisas e lazer (bate-papos, redes sociais, jogos ou vídeos).

Esses dados, somados aos antecedentes escolares acerca da sua aprendizagem sobre produção textual (perfil leitor e escritor), serão determinantes para a formação de um futuro professor com bom nível cultural, que seja um mediador de leitura e escrita.

Ao iniciar a graduação, os investigados já se dedicaram à escola por pelo menos 12 anos. Apesar desse longo tempo de estudo, no qual a leitura e a escrita são/deveriam ser constantes, muitas são as defasagens identificadas na formação das competências leitora e escritora do aluno do curso de Pedagogia.

Foi possível constatar que os investigados apontaram uma preferência maior pela leitura do que pela escrita, ou seja, grande parte não se reconhece autor/escritor. Porém, a profissão docente que desempenharão terá a escrita como instrumento indispensável.

Outro aspecto que ficou bastante claro é que tanto o perfil leitor como o escritor se consolidaram em experiências positivas na infância, seja por estímulo de familiares ou da escola.

Como tentativa de amenizar o problema, muitos cursos de Pedagogia inseriram um componente curricular voltado para práticas de leitura e escrita, objetivando principalmente auxiliar os alunos ingressantes com as defasagens relacionadas à competência leitora e escritora.

É primordial que as instituições de ensino superior repensem esta problemática e busquem alternativas para desenvolver a competência leitora e escritora dos futuros professores, já que esses profissionais serão, em grande parte, os responsáveis pela formação de novos leitores e escritores. Por outro lado, precisamos reconhecer que as instituições de ensino superior possuem uma árdua tarefa, pois a inclusão de uma única disciplina na Matriz Curricular do curso não é suficiente para suprir as dificuldades apresentadas pelos alunos. A problemática precisa ser pensada de forma abrangente, tida como responsabilidade de todos os professores. 


\section{REFERÊNCIAS}

BARDIN, Laurence. Análise de conteúdo. Tradução de Luís Antero Reto e Augusto Pinheiro. São Paulo/SP: Edições 70, 2011.

DEMO, Pedro. Professor do futuro e reconstrução do conhecimento. 6. ed. Coleção Temas Sociais. Petrópolis/RJ: Vozes, 2009.

ESTEBAN, Maria Teresa. O que sabe quem erra? Reflexões sobre avaliação e fracasso escolar. 2. ed. Petrópolis/RJ: DP \& A, 2013.

FEIMAN-NEMSER, Sharon. Teacher preparation: Structural and conceptual alternatives. National Center for Research on Teacher Education, East Lansing, MI. Issue Paper 89-5. Aug. 1989. 51 p.

FERNANDEZ, Alzira Buse. Trajetória profissional no ensino superior: um estudo sobre o professor sem formação pedagógica formal. Anais do XV ENDIPE (Encontro Nacional de Didática e Prática de Ensino) - Convergências e tensões no campo da formação e do trabalho docente: políticas e práticas educacionais. Belo Horizonte/MG, 2010. 13 p.

FERREIRA, José Luiz; CARVALHO, Maria Eulina Pessoa de. Gênero, masculinidade e magistério: horizontes de pesquisa. Olhar de Professor, Ponta Grossa/PR, v. 9, n. 1, p. 143-157, 2006.

FRANCO, Maria Laura Publisi Barbosa. Análise de conteúdo. 3. ed. Brasília/DF: Liber Livro Editora, 2008.

GARCIA, Regina Leite. Prefácio à $3^{a}$ edição. In: (org.). Para quem pesquisamos - para quem escrevemos: o impasse dos intelectuais. 3. ed. São Paulo/SP: Cortez, 2011, p. 07-10 Coleção Questões da Nossa Época, v. 31.

GATTI, Bernardete A. Formação de professores no Brasil: características e problemas. Educação \& Sociedade. Centro de Estudos Educação e Sociedade. Campinas/SP, vol. 31, n. 113, out.-dez. 2010, p. 1355-1379.

GIL, Antônio Carlos. Métodos e técnicas de pesquisa social. 6. ed. São Paulo/SP: Atlas, 2008.

GODOY, Arilda Schmidt. Introdução à pesquisa qualitativa e suas possibilidades. RAE - Revista de Administração de Empresas, São Paulo/SP, v. 35, n. 2, p. 57-63, mar./abr. 1995.

GREGÓRIO, Nadirce Barros dos Santos. A produção do gênero discursivo relatório no ensino superior. In: GHIRALDELO, Claudete Moreno. Língua portuguesa no ensino superior: experiências e reflexões. São Carlos/SP: Claraluz, 2006, p. 77-92.

GUTIERRES, Juliana Diniz et al. O perfil dos alunos do curso de Pedagogia da FURG. Anais da IX ANPED Sul - Seminário de Pesquisa em Educação da Região Sul. 2012. Disponível em: <http:// www.ucs.br/etc/conferencias/index.php/anpedsul/9anpedsul/paper/viewFile/1112/541>. Acesso em 15 jan. 2018. 5 p. 
KENSKI, Vani Moreira. O ensino e os recursos didáticos em uma sociedade cheia de tecnologias. In: VEIGA, IIma Passos Alencastro (org.). Didática: o ensino e suas relações. 9. ed. São Paulo/SP: Papirus, 2005, p. 127-147.

LERNER, Delia. Ler e escrever na escola: o real, o possível e o necessário. Tradução de Ernani Rosa. Porto Alegre/RS: Artmed, 2002.

LIMA, Vanda Moreira Machado; RINALDI, Renata Portela. Gestão educacional participativa: função da escola pública dos anos iniciais. In: TOMMASIELLO, Maria Guiomar Carneiro et al. (org.). Didática e práticas de ensino na realidade escolar contemporânea: constatações, análises e proposições. 1. ed. Araraquara/SP: Junqueira \& Marin Editores, 2012, v. 3, p. 5556-5568.

LUZZI, Marta. O ensino de língua portuguesa e a constituição do sujeito leitor/escritor. Estudos Linguísticos. São Paulo, 43 (2), maio/ago. 2014, p. 631-650.

MARTINS, Joel. A pesquisa qualitativa. In: FAZENDA, Ivani. (org.). Metodologia da pesquisa educacional. Biblioteca da Educação, Série I, v. 11. São Paulo: Cortez, 2008. p. 47-58.

MIZUKAMI, Maria da Graça Nicoletti. Formação de professores: tendências atuais. São Carlos/ SP: EdUFSCar, 1996.

OLIVEIRA, Maria Marly de. Como fazer pesquisa qualitativa. Petrópolis/RJ: Vozes, 2007.

SCHWAB, Joseph J. The practical 4: something for curriculum professors to do. Curriculum Inquiry, 13(3), Vol. 13, n. 136, p. 239-265, 1983.

SILVA, Ezequiel Theodoro da. $\mathbf{O}$ ato de ler: fundamentos psicológicos para uma nova pedagogia da leitura. 11. ed. São Paulo/SP: Cortez, 2011.

SILVA, Franklin Leopoldo e. Reflexões sobre o conceito e a função da universidade pública. Estudos Avançados, 15 (42), São Paulo/SP: USP, 2001, p. 295-304.

SOARES, Magda. A reinvenção da alfabetização. Revista Presença Pedagógica. Belo Horizonte/ MG, vol. 9, n. 52, jul.-ago. 2003, p. 15-21.

VALENTE, José Armando. A comunicação e a educação baseada no isso das tecnologias digitais de informação e comunicação. Revista UNIFESO - Humanas e Sociais. Teresópolis/RJ. Vol. I, n. 1, p. 141-166, 2014.

VELÁSQUEZ, Vanessa Cristina Zerbinato. A importância da prática do letramento no ensino superior para a prova da OAB. Virtù: Direito e Humanismo. Brasília/DF, ano 2, n. 5, v. 1. jan.-abr, 2012.

VITÓRIA, Maria Inês Corte. Qualidade do ensino superior e escrita. In: FRANCO, Maria Estela Dal Pai; MOROSINI, Marília Costa (org.). Qualidade na educação superior: dimensões e indicadores. Vol. 4. Porto Alegre/RS: EDIPUCRS, 2011. Disponível em: <http://ebooks.pucrs.br/edipucrs/qualidadedaeducacaosuperior4.pdf>. Acesso em: 17 jan. 2018.

WEISS, Maria Lúcia Lemme. Psicopedagogia Clínica: uma visão diagnóstica dos problemas de aprendizagem escolar. Rio de Janeiro/RJ: DP \& A, 2004. 